\title{
The Intrinsic Room-Temperature Ferromagnetism in ZnO:Co Thin Films Deposited by PLD
}

\author{
C. C. Wang, B. Y. Man, M. Liu, C. S. Chen, S. Z. Jiang, S. Y. Yang, S. C. Xu, X. G. Gao, and B. Hu \\ College of Physics and Electronics, Shandong Normal University, Jinan 250014, China \\ Correspondence should be addressed to B. Y. Man, byman@sdnu.edu.cn
}

Received 9 July 2011; Revised 12 October 2011; Accepted 31 October 2011

Academic Editor: Cristiana Grigorescu

Copyright () 2012 C. C. Wang et al. This is an open access article distributed under the Creative Commons Attribution License, which permits unrestricted use, distribution, and reproduction in any medium, provided the original work is properly cited.

$c$-axis preferential orientated $\mathrm{ZnO}$ :Co thin films were synthesized on $c$-plane sapphire substrates by using pulsed laser deposition (PLD) technique in an oxygen-deficient ambient. X-ray diffraction spectra, scanning electron microscopy, X-ray photoelectron spectroscopy, energy dispersive spectroscopy, UV-vis transmittance spectra, and Raman spectra were used for characterization. Ferromagnetic behavior was clearly observed at room temperature and verified to be the intrinsic property of the material. The presence of second phase was ruled out.

\section{Introduction}

Dilute magnetic semiconductors (DMSs)—semiconductors doped with a few percent of magnetic atoms-have been intensely researched in the past few years due to their promising application in spintronics devices [1]. Based on the theoretical works of Dietl et al. [2], ZnO-based DMS has attracted a considerable amount of interest due to their proposed applications of room-temperature ferromagnetism. Many reports on the observation of ferromagnetism at room temperature have been published, while surprisingly other reports did not evidence any ferromagnetism in the compounds [3-5]. These controversial results suggested that the magnetism is very sensitive to the preparation conditions. There is a continuous debate about the origin of ferromagnetism and it is not clear whether ferromagnetism is originated from secondary phases or it is an intrinsic phenomenon. It is, therefore, important to ascertain whether the ferromagnetism is related to the presence of second phases.

In this work, we report the structure and magnetic properties of $\mathrm{ZnO}$ :Co thin film with special emphasis on clarifying the origin of magnetic behavior from the perspective of structural characteristics. The Co appears to substitute for tetrahedrally coordinated $\mathrm{Zn}$ cations in the lattice and exhibits $\mathrm{a}+2$ oxidation state. For the thin films we are able to identify there is not any impurity phase, indicating an intrinsic origin to the room-temperature ferromagnetism.

\section{Experiment}

$c$-axis-oriented thin films of Co-doped $\mathrm{ZnO}$ have been grown on $c$ plane of sapphire single-crystal substrates using pulsed laser deposition (PLD) technique. The $\mathrm{Zn}_{0.95} \mathrm{Co}_{0.05} \mathrm{O}$ target used was prepared by the conventional solid state reaction technique. $\mathrm{ZnO}$ (99.99\%) powder and $\mathrm{Co}_{2} \mathrm{O}_{3}$ (99.9\%) powder as raw materials were mixed for 6 hours using a ball-mill, then uniaxially pressed (200 MPa) into a disk. The corresponding target was continuously sintered at $800^{\circ} \mathrm{C}$, $1000^{\circ} \mathrm{C}$ and $1200^{\circ} \mathrm{C}$ for 2 hours in air and then quenched to room temperature finally [6]. A pulsed $\mathrm{KrF}$ excimer laser with a wavelength of $248 \mathrm{~nm}$, a frequency of $10 \mathrm{~Hz}$, and energy density of $2 \sim 3 \mathrm{~J} / \mathrm{cm}^{2}$ was used for deposition. The target-to-substrate distance was fixed at $4 \mathrm{~cm}$. The deposition period was $15 \mathrm{~min}$. During the deposition, the substrates were kept at a constant temperature $500^{\circ} \mathrm{C}$. After deposition, the samples were slowly cooled down to room temperature. The PLD system was evacuated by a turbomolecular pump to a base pressure of $5 \times 10^{-5} \mathrm{~Pa}$. The oxygen partial pressure for film growth was varied between $10^{-4}$ and $10 \mathrm{~Pa}$. The substrates were ultrasonically cleaned in 
acetone and methanol, then rinsed in deionized water. In any case, $\mathrm{Al}_{2} \mathrm{O}_{3}$ substrates have been outgassed at $750^{\circ} \mathrm{C}$ prior to deposition.

The magnetic measurement was carried out using a MicroMag Mode 2900 alternating gradient magnetometer (AGM). The structure of the deposited films was examined using a Rigaku D/max-rB X-ray diffractormeter (XRD) and a Zeiss supra55 field emission scanning electron microscopy (FESEM). The composition of the films was measured using a PHI-5300 X-ray photoelectron spectroscopy (XPS) and an Oxford X-Max energy dispersive spectroscopy (EDS). Optical measurements were made using a U-4000 Hitachi spectrophotometer. Raman spectra were acquired from a Renishaw inVia micro-Raman spectrometer in the backscattering geometry.

\section{Results and Discussion}

The magnetic measurement results for the sample deposited under $1.3 \times 10^{-3} \mathrm{~Pa}$ oxygen partial pressure at $500^{\circ} \mathrm{C}$ are shown in Figure 1. Inset (a) shows the ferromagnetic signal of the $\mathrm{ZnO}$ :Co film before subtracting the linear diamagnetic background signal arising from the substrate. The hysteresis loops of the sample clearly indicate that the as-grown $\mathrm{ZnO}$ :Co thin film is ferromagnetism with Curie temperature $\left(T_{\mathrm{c}}\right)$ above room temperature. The coercive field of the sample is about 70 Oe. Oxides of cobalt $(\mathrm{CoO}$ $T_{N}=291 \mathrm{~K}, \mathrm{Co}_{3} \mathrm{O}_{4} T_{N}=30 \mathrm{~K}$ ) are well known to be antiferromagnetism with the Néel temperature below room temperature. Hence, the observed ferromagnetic behaviors might not be explained in terms of the formation of oxides of cobalt.

The film is highly crystallized as seen from the sharp diffraction peaks shown in Figure 2 and the full width at halfmaximum (FWHM) of the rocking curve is close to $0.33^{\circ}$. The two diffraction peaks observed around $34.4^{\circ}$ and $72.7^{\circ}$ are characteristic of the hexagonal $\mathrm{ZnO}$ wurtzite with the $c$ axis perpendicular to the substrate plane. The $c$-axis lattice constant, estimated from the peak position of the (002) line, is $0.5217 \mathrm{~nm}$, as compared to the $c$-axis lattice value of $0.5206 \mathrm{~nm}$ recorded for $\mathrm{ZnO}$ powder. The average grain size, inferred from the line broadening of (002) peak using the Scherrer formula, is found to be in the 25 nanometer range. In addition, within the detection limits of XRD, we do not find any evidence of second phase.

The surface and cross-sectional morphology were analyzed using a FESEM. Figure 3 shows the typical surface and cross-sectional images of the as-deposited film. We could see clearly that the as-deposited film consists of dense and uniformly sized grains and has a smooth surface without any voids and cracks. The existence of these small grains indicates that the nucleation density is rather high and the growth proceeds in a three-dimensional fashion. The crosssectional SEM also obviously shows the 3D columnar growth [7] mode.

XPS was also used to characterize the charge state of Co ions in the film. Figure 4 shows XPS spectrum for the as-grown film. The $\mathrm{C}$ peak in the as-grown spectrum is

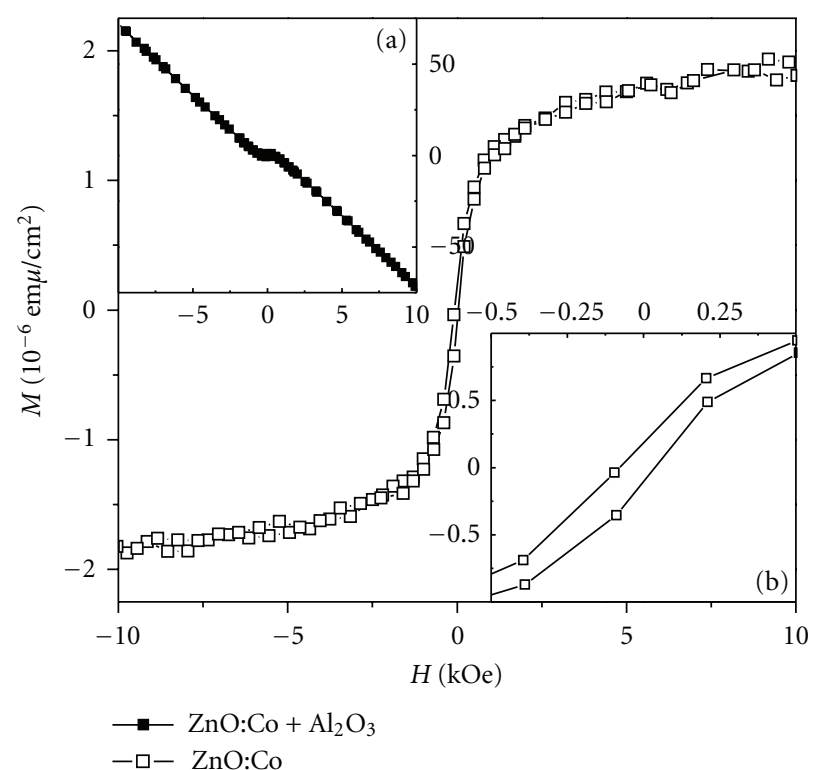

Figure 1: Magnetization curve for film deposited under $1.3 \times$ $10^{-3} \mathrm{~Pa}$ oxygen partial pressure at room temperature. Inset (a) shows magnetization curve before subtracting the diamagnetic contribution from the substrate. Inset (b) shows the magnified portion of the magnetization curve near origin.

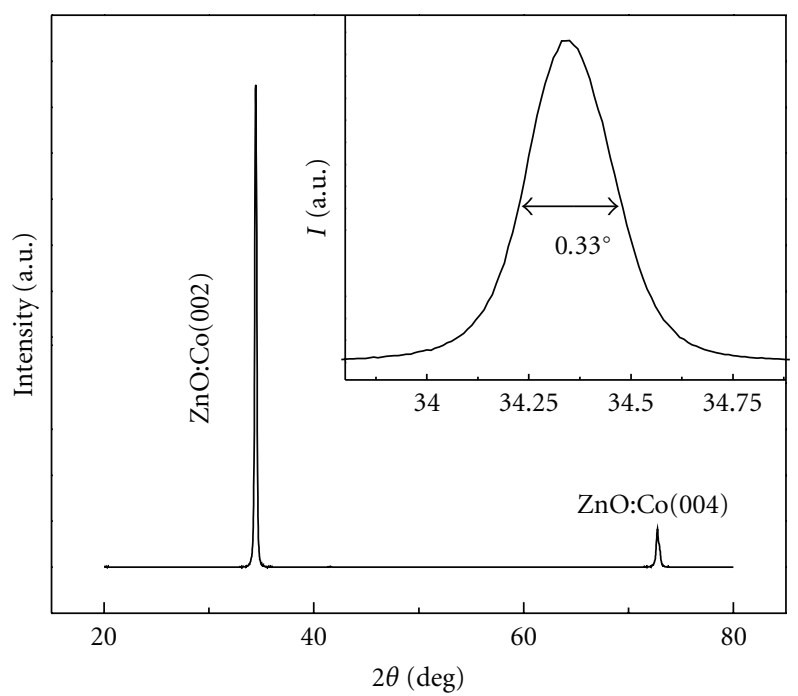

Figure 2: XRD pattern of the $\mathrm{ZnO}$ :Co grown under $1.3 \times 10^{-3} \mathrm{~Pa}$ oxygen partial pressure. The inset depicts the rocking curve of (002) reflection of the film.

presumably due to the adsorption of adventitious hydrocarbons during sample was transferred through air. The inset shows the Co $2 \mathrm{p}$ spectrum of the sample. The spectrum shows four peaks, the $2 p_{3 / 2}$ and $2 p_{1 / 2}$ doublet and shake-up resonance transitions (satellite) of these two peaks at higher binding energies. The Co $2 \mathrm{p}_{3 / 2}$ core levels for $\mathrm{Co}-\mathrm{O}$ bonding is $781.4 \mathrm{eV}$, and the energy difference between Co $2 \mathrm{p}_{3 / 2}$ and Co $2 \mathrm{p}_{1 / 2}$ is $15.4 \mathrm{eV}$, which matches that of standard $\mathrm{CoO}$, indicating the presence of a high-spin divalent state of $\mathrm{Co}$ in these samples $[8,9]$. Thus, within the detection limits of 


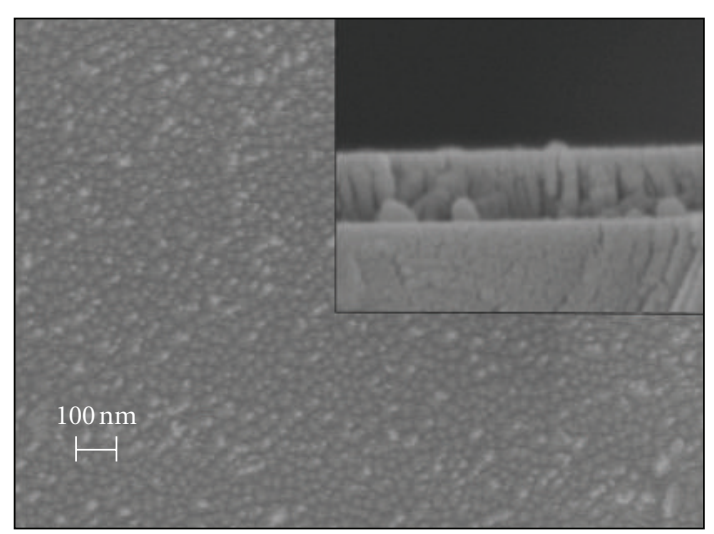

FIgURE 3: SEM and cross-sectional SEM images of the as-grown film under $1.3 \times 10^{-3} \mathrm{~Pa}$ oxygen partial pressure.

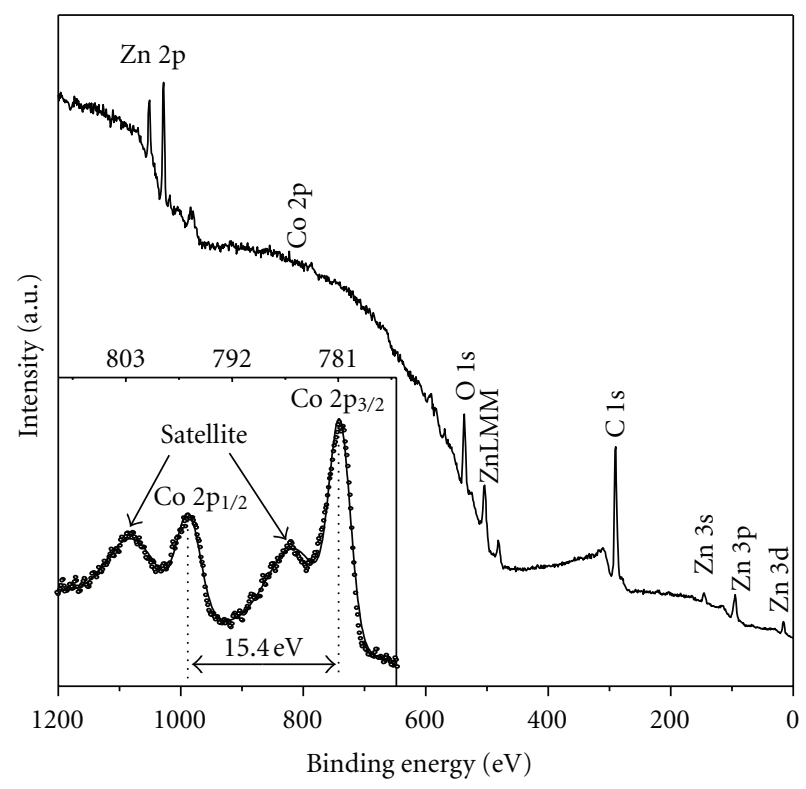

Figure 4: The full-range XPS spectra of the $\mathrm{ZnO}$ :Co thin film, revealing only $\mathrm{Zn}, \mathrm{Co}, \mathrm{O}$, and $\mathrm{C}$ peaks. The inset shows the Co $2 \mathrm{p}$ spectrum of the sample.

the spectrometer, we can rule out metallic Co as the source of the observed ferromagnetism.

EDS is used to measure the percentage of cobalt in the ZnO:Co film. The EDS data taken at a number of locations throughout the specimen reveal a uniform distribution of Co dissolved in $\mathrm{ZnO}$ lattices. The cobalt content of the film deposited under $1.3 \times 10^{-3} \mathrm{~Pa}$ oxygen partial pressure is $6.6 \%$, that is, the dopant concentration in the film is higher than in the target. Similar results of the transition metal enrichment in doped $\mathrm{ZnO}$ films grown by PLD have been reported [10-12]. The reasons have been analyzed by the higher sputter yield of the $\mathrm{Zn}$ atoms than Co atoms from the thin film surface, which caused by the high energy ions (several hundred eV [13]) in the laser ablation plasma plume. The preferential sputtering from the film surface was caused by two factors: surface binding effects and mass difference effects [11]. For ZnO:Co alloy film, sputtering from the surface is strongly determined by the surface binding energy (BE) of the metal atoms and to a lesser extent by their atomic mass [13]. Thus, the sputter yield is higher for $\mathrm{Zn}$ because it has the lower surface energy (the surface $\mathrm{BE}$ for $\mathrm{Zn}$ of $\mathrm{ZnO}$ is $3.04 \mathrm{eV}$, while the surface $\mathrm{BE}$ for $\mathrm{Co}$ of $\mathrm{Co}_{3} \mathrm{O}_{4}$ is $6.05 \mathrm{eV}$ [13]), resulting in a higher cobalt concentration in the film than in the target.

Evidence for Co substitution in the $\mathrm{ZnO}$ lattice for our film can be inferred from optical absorption measurements. Figure 5 shows the optical transmission for $\mathrm{ZnO}$ :Co film. An undoped $\mathrm{ZnO}$ film is included as reference. Three absorption peaks are observed in the doped film and labelled as 1,2, and 3 . The absorption peaks at approximately 566, 611, and $655 \mathrm{~nm}$ can be identified as the d-d transitions from the ${ }^{4} A_{2}(E)$ ground state toward ${ }^{2} A_{1}(G),{ }^{4} T_{1}(P)$, and ${ }^{2} E(G)$ excited states of $\mathrm{Zn}$ substituted $\mathrm{Co}^{2+}$ ions in $\mathrm{ZnO}[14,15]$. This shows the presence of cobalt in a tetrahedral crystal field in the +2 state. The Co doping also leads to bandgap narrowing, which is typically interpreted as due to the sp$\mathrm{d}$ exchange interactions between the band electrons and the localized d electrons of Co ions [16]. Based on the above experiment results, we can find that the Co cations have successfully entered into the hexagonal wurtzite structure and substituted for $\mathrm{Zn}$ cations sites in the $\mathrm{ZnO}$ lattice.

The Raman measurements were performed in the backscattering geometry at room temperature with a $514.5 \mathrm{~nm}$ $(2.4 \mathrm{eV}) \mathrm{Ar}^{+}$laser as an excitation source. The Raman spectra of the $\mathrm{Zn}_{0.95} \mathrm{Co}_{0.05} \mathrm{O}$ target (inset of Figure 6) are dominated by five broad peaks. The peaks at 198, 322, and $429 \mathrm{~cm}^{-1}$ can be attributed to the $2 \mathrm{E}_{2 \mathrm{~L}} ; 2 \mathrm{TA}, \mathrm{E}_{2 \mathrm{H}}-\mathrm{E}_{2 \mathrm{~L}}$, and $\mathrm{E}_{2 \mathrm{H}}$ modes, respectively [17]. The vibrations at around 230 and $530 \mathrm{~cm}^{-1}$ are assigned to the acoustic-phonon branch at the zone boundary and shallow donor defects bound on the Co sites, respectively [18]. Figure 6 shows the spectra of Co-doped $\mathrm{ZnO}$ deposited under $1.3 \times 10^{-3} \mathrm{~Pa}$ oxygen partial pressure. In addition to the phonon modes from the sapphire substrate (the peaks labelled with " $s$ ") and the peaks which also can be observed in the target, additional modes are observed. It also shows that the $E_{2 H}$ peak substantially reduced in the film compared with that in the target. The $\mathrm{Zn}_{0.95} \mathrm{Co}_{0.05} \mathrm{O}$ target is polycrystalline ceramics, thereby the intensity of $\mathrm{E}_{2 \mathrm{H}}$ peak is high and FWHM is also large. However, the $\mathrm{ZnO}$ :Co thin film is single crystal. The pronounced weakening of $E_{2 H}$ peak is the consequence of the structural defect formation and local lattice distortions induced by doping $[8,18,19]$. The peaks at $380,407,576$ and $670 \mathrm{~cm}^{-1}$ can be attributed to the $A_{1}(T O), E_{1}(T O)$, $\mathrm{A}_{1}(\mathrm{LO})$ and $\mathrm{TA}+\mathrm{LO}$ modes, respectively [17]. The mode of $644 \mathrm{~cm}^{-1}$ which is also revealed in $\mathrm{Fe}, \mathrm{Sb}, \mathrm{Al}, \mathrm{N}$, and $(\mathrm{Mn}$, $\mathrm{Co}$ ) doped $\mathrm{ZnO}$ may correlate with $\mathrm{Zn}$ interstitials or oxygen vacancies by the impurity doping $[20,21]$. The mode of $694 \mathrm{~cm}^{-1}$ is still uncertain. Sudakar et al. tentatively assigned the mode observed in $\mathrm{ZnO}$ :Co samples at about $690 \mathrm{~cm}^{-1}$ to the $\mathrm{Zn}-\mathrm{O}-\mathrm{Co}$ local vibration [22]. The peak at $134 \mathrm{~cm}^{-1}$ due to scattering on $\mathrm{E}_{2 \mathrm{~g}}$ phonon of hcp-Co [23] and the peaks at about 146 and $300 \mathrm{~cm}^{-1}$ related to $\mathrm{CoO}$ magnons [24, 25] were absent in our sample. Thus, for the thin film we are able to identify no mode of impurity phases. This provides further 


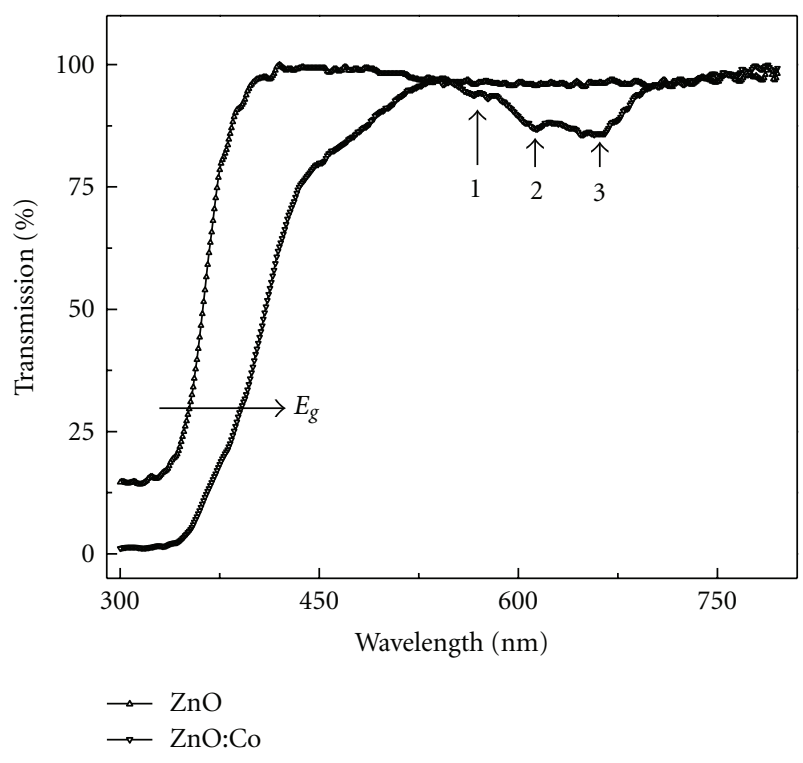

FIGURE 5: Room-temperature optical transmittance spectrum for $\mathrm{ZnO}: \mathrm{Co}$ and $\mathrm{ZnO}$ thin films.

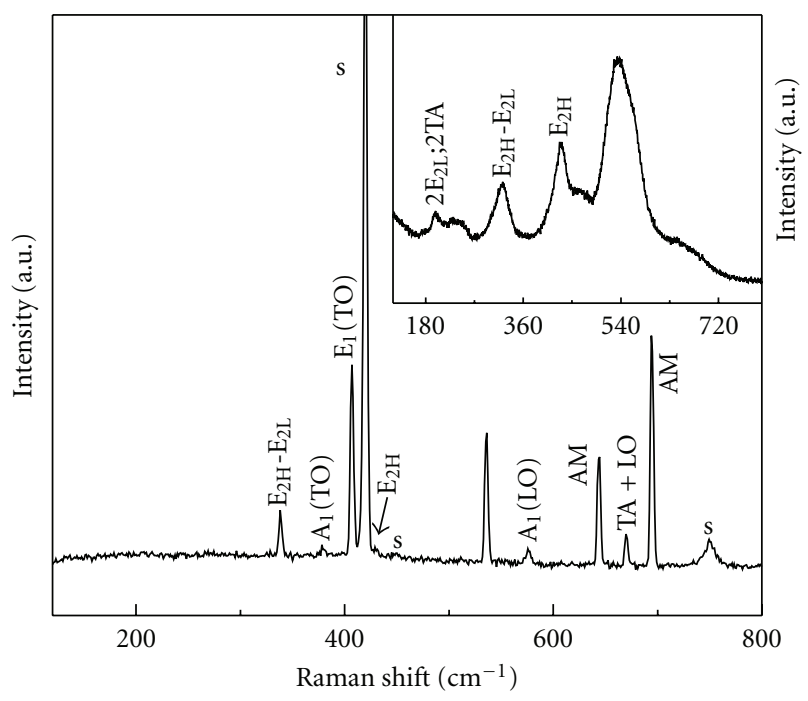

Figure 6: Room-temperature Raman spectrum of $\mathrm{ZnO}$ :Co thin film. Peaks attributed to the substrate are labelled with " $\mathrm{s}$ ". The inset shows the Raman spectrum of the $\mathrm{Zn}_{0.95} \mathrm{Co}_{0.05} \mathrm{O}$ target.

evidence for the observed ferromagnetism in the samples is not induced by phase segregation.

The samples are carefully characterized using XRD, XPS, UV-Vis, and Raman and we are able to make a convincing case that there are no impurity phases present, at least within the limitations of these characterization techniques. Having ruled out the possibility of the presence of second phase through our structural and optical investigations, we infer that the presence of second phase could not be the cause of the observed room-temperature ferromagnetism. Hence, we conclude that the observed room-temperature ferromagnetism is an inherent property of the material. There are several mechanisms proposed in the literature regarding the origin of ferromagnetism in DMSs [26]. The exact mechanism of intrinsic ferromagnetism in TM-doped oxides is still under debate. The Ruderman-Kittel-KasuyaYosida (RKKY) interaction is based on free electrons, but $\mathrm{ZnO}$ cannot transform into a metal at such a low doping. Direct interactions such as double-exchange or superexchange cannot be responsible for the ferromagnetism because the magnetic cations are dilute in our samples. Coey et al. proposed that ferromagnetic exchange in dilute ferromagnetic oxides is mediated by shallow donor electrons that form bound magnetic polarons, which overlap to create a spin-split impurity band [27]. However, a carrier-mediated interpretation for the room-temperature ferromagnetism has also been proposed [28]. Co dopant states were successfully identified and positioned in the host $\mathrm{ZnO}$ bands [29]. An observable carrier density on the order of less than 0.1 electron per Co ion could stabilize the ferromagnetic coupling against the ambient conditions according to the band-coupling model was demonstrated [30,31]. The origin of the room-temperature ferromagnetism in the $\mathrm{ZnO}: \mathrm{Co}$ films will be a study emphasis in our further research.

\section{Conclusions}

In conclusion, we have grown $\mathrm{ZnO}$ :Co thin films on $\mathrm{Al}_{2} \mathrm{O}_{3}$ (0001) substrates by PLD. Ferromagnetic behaviour was clearly observed at room temperature for the $\mathrm{ZnO}$ :Co films. The XRD, XPS, EDS, UV-Vis, and Raman analysis demonstrated that cobalt can be uniformly incorporated into the wurtzite structure and substitute for $\mathrm{Zn}$ cations sites in $\mathrm{ZnO}$ lattice without phase segregation. There is no evidence for the formation of either metallic Co or CoOx particles in the thin film, indicating an intrinsic origin to the ferromagnetism. The growth of these ferromagnetic films opens the route for the fabrication of spin-based electronics.

\section{Acknowledgments}

The authors are grateful for the financial support of the National Natural Science Foundation of China (11047161, 10874103) and the Postdoctoral Innovation Projects of Shandong (200903036).

\section{References}

[1] S. A. Wolf, D. D. Awschalom, R. A. Buhrman et al., "Spintronics: a spin-based electronics vision for the future," Science, vol. 294, no. 5546, pp. 1488-1495, 2001.

[2] T. Dietl, H. Ohno, F. Matsukura, J. Cibert, and D. Ferrand, "Zener model description of ferromagnetism in zinc-blende magnetic semiconductors," Science, vol. 287, no. 5455, pp. 1019-1022, 2000.

[3] Z. Jin, T. Fukumura, M. Kawasaki et al., "High throughput fabrication of transition-metal-doped epitaxial $\mathrm{ZnO}$ thin films: a series of oxide-diluted magnetic semiconductors and their properties," Applied Physics Letters, vol. 78, no. 24, pp. 3824-3826, 2001.

[4] S. Kolesnik and B. Dabrowski, "Absence of room temperature ferromagnetism in bulk Mn-doped ZnO," Journal of Applied Physics, vol. 96, no. 9, pp. 5379-5381, 2004. 
[5] G. Lawes, A. S. Risbud, A. P. Ramirez, and R. Seshadri, "Absence of ferromagnetism in Co and $\mathrm{Mn}$ substituted polycrystalline ZnO," Physical Review B, vol. 71, no. 4, pp. 1-5, 2005.

[6] S. Y. Yang, B. Y. Man, M. Liu et al., "Structural, optical and magnetic properties of $\mathrm{Zn}_{1-x} \mathrm{Co}_{x} \mathrm{O}$ dilute magnetic semiconductors thin films by pulsed laser deposition," Physica B, vol. 405, no. 18, pp. 4027-4031, 2010.

[7] I. Petrov, P. B. Barna, L. Hultman, and J. E. Greene, "Microstruc-tural evolution during film growth," Journal of Vacuum Science \& Technology, vol. 21, no. 5, pp. S117-SS128, 2003.

[8] X. Wang, J. Xu, B. Zhang et al., "Signature of intrinsic high-temperature ferromagnetism in cobalt-doped zinc oxide nanocrystals," Advanced Materials, vol. 18, no. 18, pp. 24762480, 2006.

[9] S.-W. Lim, D.-K. Hwang, and J.-M. Myoung, "Observation of optical properties related to room-temperature ferromagnetism in co-sputtered $\mathrm{Zn}_{1-x} \mathrm{Co}^{x} \mathrm{O}$ thin films," Solid State Communications, vol. 125, no. 5, pp. 231-235, 2003.

[10] C. B. Fitzgerald, M. Venkatesan, J. G. Lunney, L. S. Dorneles, and J. M. D. Coey, "Cobalt-doped $\mathrm{ZnO}$ - a room temperature dilute magnetic semiconductor," Applied Surface Science, vol. 247, no. 1-4, pp. 493-496, 2005.

[11] L. S. Dorneles, D. O’Mahony, C. B. Fitzgerald et al., "Structural and compositional analysis of transition-metal-doped $\mathrm{ZnO}$ and GaN PLD thin films," Applied Surface Science, vol. 248, no. 1-4, pp. 406-410, 2005.

[12] M. Ivill, S. J. Pearton, and S. rawal, "Structure and magnetism of cobalt-doped $\mathrm{ZnO}$ thin films," New Journal of Physics, vol. 10, Article ID 065002, 2008.

[13] J. B. Malherbe, S. Hofmann, and J. M. Sanz, "Preferential sputtering of oxides: a comparison of model predictions with experimental data," Applied Surface Science, vol. 27, no. 3, pp. 355-365, 1986.

[14] P. Koidl, "Optical absorption of $\mathrm{Co} 2+$ in ZnO," Physical Review $B$, vol. 15, no. 5, pp. 2493-2499, 1977.

[15] S. Ramachandran, A. Tiwari, and J. Narayan, " $\mathrm{Zn}_{0.9} \mathrm{Co}_{0.1} \mathrm{O}-$ based diluted magnetic semiconducting thin films," Applied Physics Letters, vol. 84, no. 25, Article ID 5255, 3 pages, 2004.

[16] K. J. Kim and Y. R. Park, "Spectroscopic ellipsometry study of optical transitions in $\mathrm{Zn}_{1-x} \mathrm{Co}_{x} \mathrm{O}$ alloys," Applied Physics Letters, vol. 81, no. 8, pp. 1420-1422, 2002.

[17] C. Raman, A.-L. Esther, I. Jordi et al., "Temperature dependence of Raman scattering in ZnO," Physical Review B, vol. 75, no. 16, Article ID 165202, 2007.

[18] X. F. Wang, J. B. Xu, X. J. Yu, K. Xue, J. G. Yu, and X. J. Zhao, "Structural evidence of secondary phase segregation from the Raman vibrational modes in $\mathrm{Zn}_{1-x} \mathrm{Co}_{x} \mathrm{O}(0<x<0.6)$," Applied Physics Letters, vol. 91, Article ID 031908, 2007.

[19] K. Samanta, P. Bhattacharya, R. S. Katiyar, W. Iwamoto, P. G. Pagliuso, and C. Rettori, "Raman scattering studies in dilute magnetic semiconductor $\mathrm{Zn}_{1-x} \mathrm{Co}_{x} \mathrm{O}$," Physical Review B, vol. 73, no. 24, Article ID 245213, 5 pages, 2006.

[20] C. Bundesmann, N. Ashkenov, M. Schubert et al., "Raman scattering in $\mathrm{ZnO}$ thin films doped with $\mathrm{Fe}, \mathrm{Sb}, \mathrm{Al}, \mathrm{Ga}$, and $\mathrm{Li}$," Applied Physics Letters, vol. 83, no. 10, pp. 1974-1976, 2003.

[21] C. L. Du, Z. B. Gu, M. H. Lu et al., "Raman spectroscopy of (Mn, Co)-codoped ZnO films," Journal of Applied Physics, vol. 99, no. 12, Article ID 123515, 4 pages, 2006.

[22] C. Sudakar, P. Kharel, G. Lawes, R. Suryanarayanan, R. Naik, and V. M. Naik, "Raman spectroscopic studies of oxygen defects in Co-doped $\mathrm{ZnO}$ films exhibiting room-temperature ferromagnetism," Journal of Physics Condensed Matter, vol. 19, no. 2, Article ID 026212, 2007.
[23] A. F. Goncharov, J. Crowhurst, and J. M. Zaug, "Elastic and vibrational properties of cobalt to $120 \mathrm{GPa}$," Physical Review Letters, vol. 92, no. 11, Article ID 115502, 4 pages, 2004.

[24] R. R. Hayes and C. H. Perry, "Magnetic excitations in cobalt oxide," Solid State Communications, vol. 13, no. 11, pp. 19151917, 1973.

[25] H.-H. Chou and H. Y. Fan, "Light scattering by magnons in $\mathrm{CoO}, \mathrm{MnO}$, and $\alpha$-MnS," Physical Review B, vol. 13, Article ID 3924, 1976.

[26] V. A. Fonoberov, K. A. Alim, A. A. Balandin, F. Xiu, and J. Liu, "Photoluminescence investigation of the carrier recombination processes in $\mathrm{ZnO}$ quantum dots and nanocrystals," Physical Review B, vol. 73, no. 16, Article ID 165317, 2006.

[27] J. M. D. Coey, M. Venkatesan, and C. B. Fitzgerald, "Donor impurity band exchange in dilute ferromagnetic oxides," Nature Materials, vol. 4, no. 2, pp. 173-179, 2005.

[28] K. R. Kittilstved, D. A. Schwartz, A. C. Tuan, S. M. Heald, S. A. Chambers, and D. R. Gamelin, "Direct kinetic correlation of carriers and ferromagnetism in $\mathrm{Co}^{2+}: \mathrm{ZnO}$," Physical Review Letters, vol. 97, no. 3, Article ID 037203, 2006.

[29] C. D. Pemmaraju, R. Hanafin, T. Archer, H. B. Braun, and S. Sanvito, "Impurity-ion pair induced high-temperature ferromagnetism in Co-doped ZnO," Physical Review B, vol. 78, no. 5, Article ID 054428, 2008.

[30] A. Walsh, J. L. F. Da Silva, S. H. Wei et al., "Nature of the band gap of $\operatorname{In}_{2} \mathrm{O}_{3}$ revealed by first-principles calculations and X-ray spectroscopy," Physical Review Letters, vol. 100, no. 16, Article ID 167402, 2008.

[31] X. F. Wang, F. Q. Song, Q. Chen et al., "Scaling dopant states in a semiconducting nanostructure by chemically resolved electron energy-loss spectroscopy: a case study on Co-doped ZnO," Journal of the American Chemical Society, vol. 132, no. 18, pp. 6492-6497, 2010. 

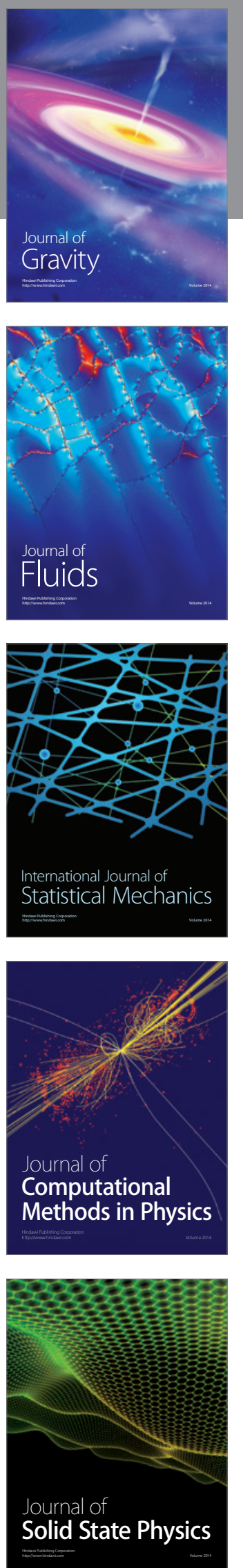

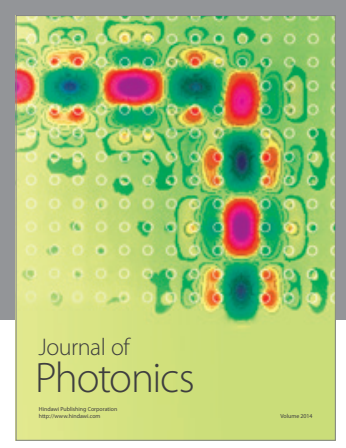

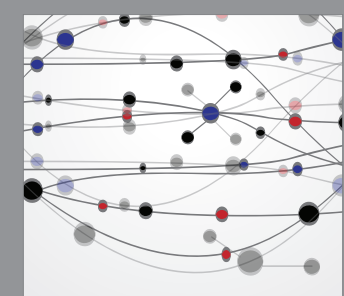

The Scientific World Journal
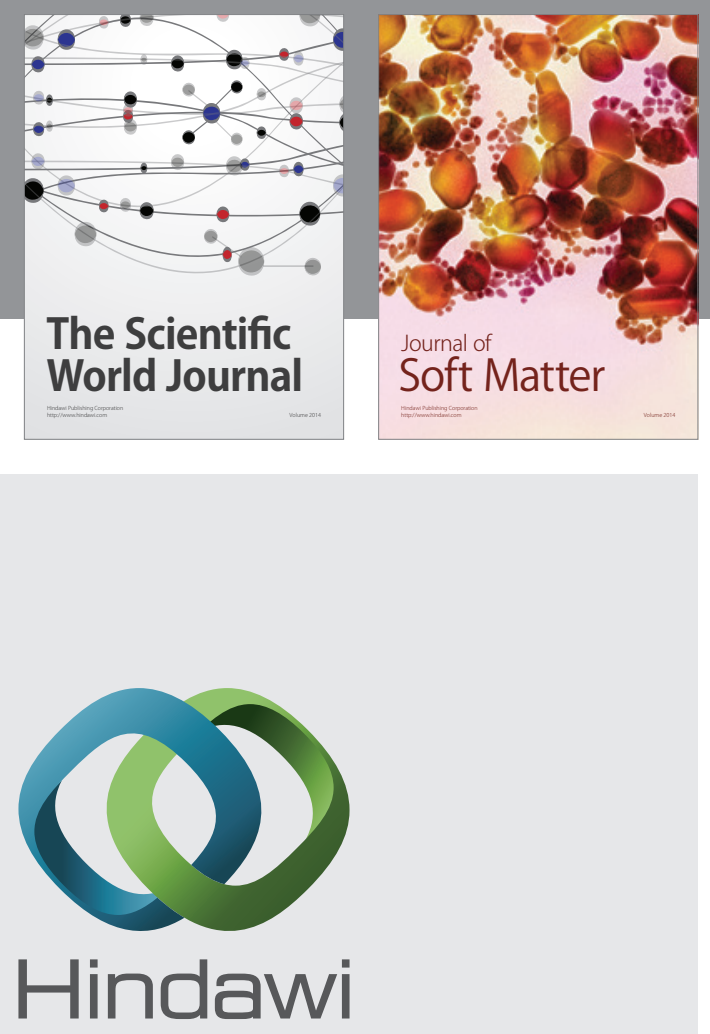

Submit your manuscripts at

http://www.hindawi.com
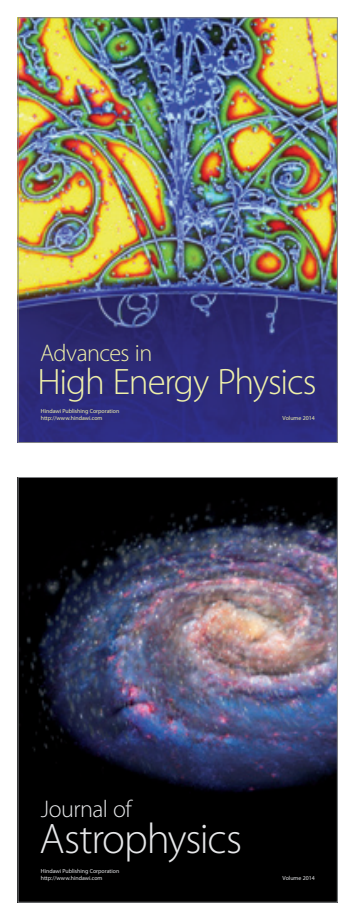
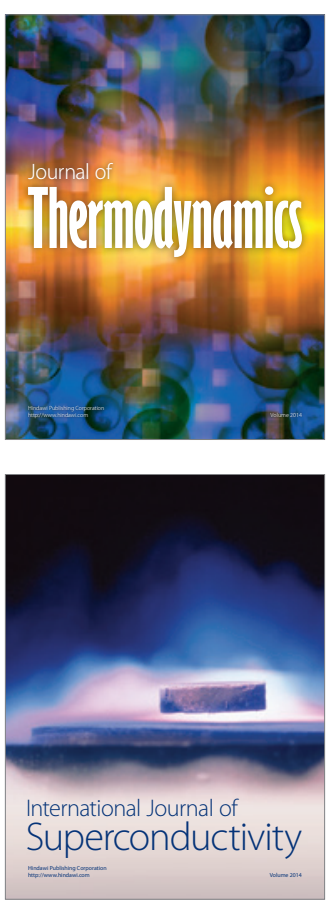
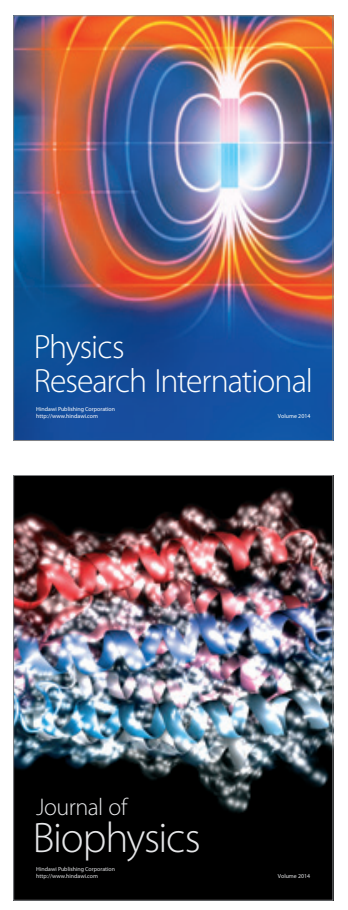
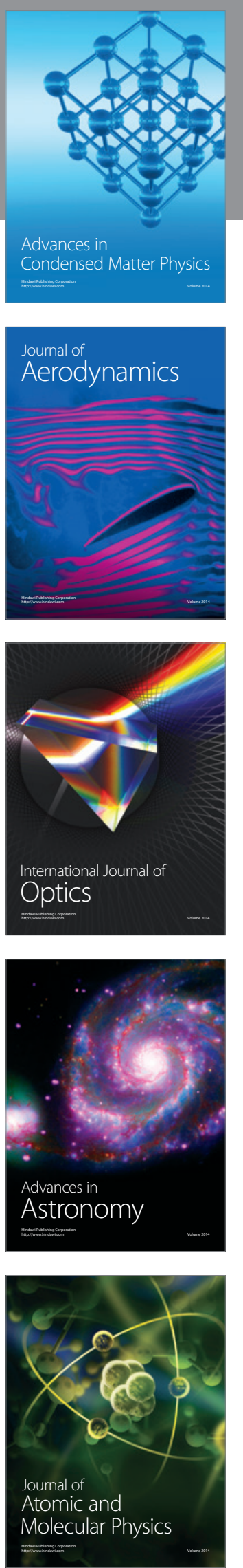